\title{
ILF2 promotes anchorage independence through direct regulation of PTEN
}

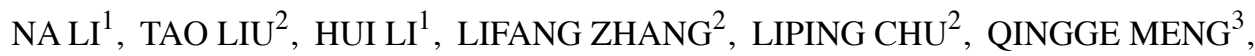 \\ QINZENG QIAO ${ }^{2}$, WEIKUN HAN ${ }^{2}$, JUNHUI ZHANG $^{1}$, MINYING GUO $^{1}$ and JIA ZHAO ${ }^{4}$ \\ ${ }^{1}$ Pathology Department, Xingtai Medical College; ${ }^{2}$ Department of Internal Medicine, Civil Administration General \\ Hospital of Hebei; ${ }^{3}$ Department of Internal Medicine, Xingtai Medical College; ${ }^{4}$ Department of Internal Medicine, \\ The Third Affiliated Hospital of Xingtai Medical College, Xingtai, Hebei 054000, P.R. China
}

Received May 17, 2018; Accepted May 9, 2019

DOI: $10.3892 / 01.2019 .10510$

\begin{abstract}
Anoikis is a specific form of programmed cell death induced by loss of contact between cells and extracellular matrices or other cells. Only tumor cells that are resistant to anoikis can survive in the state of detachment from the primary tissue during the early stages of metastasis. The ability to resist anoikis is crucial for cancer cell metastasis. ILF2 is a proto-oncogene previously studied in glioma, NSCLC, esophageal cancer and pancreatic ductal carcinoma. The results from the present study revealed that the transcription factor interleukin enhancer-binding factor 2 (ILF2) was highly expressed in non-small cell lung cancer (NSCLC) cell lines compared with in normal cell lines. ChIP and luciferase reporter gene assays demonstrated that ILF2 inhibited the expression level of the tumor suppressor gene phosphatase and tensin homolog (PTEN) by directly binding to its upstream regulatory region. Furthermore, the results from the detection of cell adhesion and apoptosis in cell suspension culture demonstrated that this mechanism enabled NSCLC cells to reduce adherence to the matrix and to survive in this abnormal state. These results suggested that ILF2 may promote the anchorage-independence of NSCLC cells through the suppression of PTEN.
\end{abstract}

Correspondence to: Professor Tao Liu, Department of Internal Medicine, Civil Administration General Hospital of Hebei, 293 Quannanxi Street, Qiaoxi, Xingtai, Hebei 054000, P.R. China E-mail: liutao54321@126.com

Abbreviations: NSCLC, non-small cell lung cancer; PTEN, phosphatase and tensin homolog deleted on chromosome ten; ILF2, interleukin enhancer-binding factor 2; ChIP, chromatin immunoprecipitation; ENCODE, Encyclopedia of DNA Elements

Key words: non-small cell lung cancer, anchorage independence, interleukin enhancer binding factor 2, phosphatase and tensin homolog, transcriptional regulation

\section{Introduction}

Lung cancer is one of the most lethal diseases worldwide, and is responsible for $\sim 1.2$ million cases of mortality each year (1). According to the pathological type, lung cancer can be divided into small cell lung cancer and non-small cell lung cancer (NSCLC). NSCLC accounts for $85 \%$ of all lung cancer cases. Squamous cell carcinoma represents $\sim 30 \%$ of small cell lung cancer cases, and non-squamous cell carcinoma accounts for $\sim 70 \%$. NSCLC is the leading cause of tumor-associated mortality in the United States and Europe. The majority of patients $(\sim 60 \%)$ are diagnosed with locally advanced or metastatic NSCLC, and the 5-year survival rate is only $\sim 5 \%$. Vascular endothelial growth factor (VEGF) (2) and epidermal growth factor receptor (3) are currently the main therapeutic targets in NSCLC. However, $>40 \%$ of patients with NSCLC develop tumor recurrence, even when they have received early treatment (4). Therefore, the specific mechanisms of NSCLC development, and novel therapeutic targets, require further investigation.

Apoptosis is a type of gene-encoded spontaneous cell death that occurs during cell growth, differentiation, development and pathology. It is also known as programmed cell death (5). Normal epithelial or endothelial cells are adhesive-dependent, and their survival depends on cell-cell and cell-matrix signaling (6). However, tumor cells can survive without adhesion, which is named anchorage independence (7). Anoikis is a specific form of programmed cell death induced by loss of contact between cells and extracellular matrices or other cells. Progress on the determination of anoikis-related genes has been made. It has been reported that the decrease of B-cell lymphoma-extra large (Bcl-XL) protein expression induces a significant increase in ovarian cancer cell anoikis; however, it has no effect on cells that are attached to other cells (8). Mutation or loss of heterozygosis of the phosphatase and tension homolog (PTEN) gene is closely associated with the occurrence and development of tumors, including glioblastoma and prostate cancer. It can also mediate the regulation of anoikis signaling (9). In addition, integrins serve a crucial role in anchorage independence as a central signaling pathway between cells and matrix (10). 
Interleukin enhancer binding factor 2 (ILF2) is also known as nuclear factor 45. In the past few years, ILF2 has been extensively studied in tumors. For example, ILF2 is overexpressed in various types of malignancy, including glioma, NSCLC and esophageal cancer, and promotes their development (11-13). Therefore ILF2 upregulation may be necessary for cancer cell progression. In addition, recent studies reported that ILF2 expression is associated with tumor size in pancreatic ductal carcinoma (PDAC) $(14,15)$. Furthermore, ILF2 can be a valuable prognostic indicator of PDAC survival (15). Lee et al (16) reported that ILF2 expression is high in liver cancer tissues by using immunohistochemistry and western blotting. However, the specific function of ILF2 and its mechanism underlying tumorigenesis require further investigation.

PTEN was the first tumor suppressor gene with phosphatase activity to be discovered (17). Numerous degrees of PTEN gene mutation or loss exist in various types of tumor tissues, cell lines and xenografts. PTEN is involved in many important intracellular pathways and serves therefore crucial roles in suppressing the occurrence and development of tumors. PTEN blocks the phosphoinositide 3-kinase $(\mathrm{PI} 3 \mathrm{~K}) /$ protein kinase $\mathrm{B}$ signaling pathway by decreasing phosphatidylinositol $(3,4,5)$-trisphosphate (PIP3) levels to promote apoptosis (18). PTEN is a diphosphatase, which activates PI3K to dephosphorylate PIP3. This reaction blocks PI3K-regulated growth factor signaling pathways and maintains cell growth during normal growth cycles (19). PTEN can also inhibit focal adhesion kinase phosphorylation to suppress cell migration (20). In addition, PTEN inhibits tumor angiogenesis through regulation of VEGF expression (21).

Although ILF2 has been previously reported in NSCLC, the present study aimed to examine the function of ILF2 in a completely novel way. The results from this study demonstrated that ILF2 was highly expressed in NSCLC cell lines and was associated with poor patient prognosis, according to an online database. In addition, ILF2 reduced cell-matrix adhesion and promoted anchorage independence. Further analyses revealed that ILF2 directly bound to the PTEN gene and regulated its expression. The results suggested that ILF2 may achieve these functions through $P T E N$ regulation.

\section{Materials and methods}

Cell culture. HUVEC-C, HBEC-5i, BEAS-2B, A549, $\mathrm{H} 460, \mathrm{H} 1155$ and H1299 cell lines were obtained from the American Type Culture Collection (Manassas, VA, USA). HUVEC-C is a human umbilical vein endothelium cell line. HBEC-5i is a human cerebral microvascular endothelium cell line. BEAS-2B is a human normal lung epithelial cell line. A549, H460, H1155 and H1299 are NSCLC cell lines. HUVEC-C cells were maintained in Kaighn's Modification of Ham's F-12 medium (Gibco; Thermo Fisher Scientific, Inc., Waltham, MA, USA) supplemented with $10 \%$ fetal bovine serum (FBS; Gibco; Thermo Fisher Scientific, Inc.), $0.1 \mathrm{mg} / \mathrm{ml}$ heparin (cat. no. H3393; Sigma-Aldrich; Merck $\mathrm{KGaA}$, Darmstadt, Germany) and $40 \mu \mathrm{g} / \mathrm{ml}$ endothelial cell growth supplement (ECGS; cat. no. 354006; BD Biosciences, San Jose, CA, USA). HBEC-5i cells were maintained in Dulbecco's modified Eagle's medium/F12 (Gibco; Thermo
Fisher Scientific, Inc.) supplemented with 10\% FBS and $40 \mu \mathrm{g} / \mathrm{ml}$ ECGS. BEAS-2B, A549, H460, H1155 and H1299 cells were maintained in RPMI-1640 medium (Gibco; Thermo Fisher Scientific, Inc.) supplemented with 10\% FBS. All cells were cultured at $37^{\circ} \mathrm{C}$ in a humidified incubator containing $5 \% \mathrm{CO}_{2}$.

Adhesion assay. Cell culture dishes (diameter, 60-mm) were covered with fibronectin (500 $\mu \mathrm{l}, 10 \mu \mathrm{g} / \mathrm{ml}$; Sigma-Aldrich; Merck $\mathrm{KGaA}$ ) and incubated in a cell incubator overnight. HUVEC-C, HBEC-5i, A549 or H460 were transfected with control, shILF2, ILF2, shPTEN and PTEN. Dishes were washed twice with PBS (Thermo Fisher Scientific, Inc.), and $2 \times 10^{5}$ HUVEC-C, HBEC-5i, A549 or H460 cells in normal medium were seeded in each dish and incubated for $30 \mathrm{~min}$ at $37^{\circ} \mathrm{C}$ in a cell culture incubator. The media was discarded, and cells were washed twice with PBS. Crystal violet $[0.05 \%$ $(\mathrm{w} / \mathrm{v})$ ] was used to stain adhered cells for $10 \mathrm{~min}$ at room temperature, and plates were imaged by light microscopy (magnification, x100). Finally, the number of cells that were stained were counted.

Cell death detection by ELISA. To examine the ability of anchorage independence, cells transfected with control, shILF2, ILF2, shPTEN and PTEN were seeded $\left(\sim 2 \times 10^{5}\right)$ in low-attachment (Corning Inc., Corning, NY, USA) and normal surface 24 -well plates at $37^{\circ} \mathrm{C}$ cell culture incubator. Cells that normally grow adherently cannot adhere to low-attachment (PolyHEMA-coated) 24-well plates. This can be used to simulate the detachment of cells from the matrix. According to the manufacturer's protocol, a Cell Death Detection ELISA PLUS kit (cat. no. 11774425001; Roche Diagnostics, Basel, Switzerland) was used to assess cell apoptosis. Apoptotic cells were measured using a microplate reader at $405 \mathrm{~nm}$. The ELISA kit was used to detect the level of apoptosis. It determines the level of apoptosis by detecting the DNA-ladder produced by endogenous restriction endonuclease cleavage during apoptosis $(22,23)$.

RNA isolation and reverse transcription-quantitative polymerase chain reaction $(R T-q P C R)$. Total RNA was isolated from cells with TRIzol ${ }^{\circledR}$ reagent (Invitrogen; Thermo Fisher Scientific, Inc.) and reverse transcribed with oligo dT (Takara Biotechnology Co., Ltd., Dalian, China). The reverse transcription temperature protocol was $1 \mathrm{~h}$ at $42^{\circ} \mathrm{C}$ and $10 \mathrm{~min}$ at $72^{\circ} \mathrm{C}$ according to the manufacturer's protocol. RT-qPCR was performed with Ex Taq ${ }^{\circledR}$ polymerase (Takara Biotechnology Co., Ltd.), and the cycling conditions were as follows: Initial denaturation for $3 \mathrm{~min}$ at $95^{\circ} \mathrm{C}$, followed by 31 cycles of $15 \mathrm{sec}$ at $95^{\circ} \mathrm{C}, 15 \mathrm{sec}$ at $55^{\circ} \mathrm{C}$ and $30 \mathrm{sec}$ at $72^{\circ} \mathrm{C}$, with a final extension for $7 \mathrm{~min}$ at $72^{\circ} \mathrm{C}$. The sequences of the primers were designed as follows: ILF2 (gene ID: 3608), forward 5'-AGG CCCTTTGTACCACATATC-3', reverse 5'-ATCCTGTGC TCTTAGGCTTTC-3' (reverse); and GAPDH (gene ID: 2597), forward 5'-GATTCCACCCATGGCAAATTC-3' and reverse 5'-GTCATGAGTCCTTCCACGATAC-3'. The 2- ${ }^{-\Delta \mathrm{Cq}}$ method was used to normalize the expression to GAPDH (24).

Western blotting. For protein extraction, $2 \times 10^{6}$ cells were incubated in lysis buffer that was composed of $100 \mu 150 \mathrm{mM}$ 
Tris- $\mathrm{HCl}(\mathrm{pH} 8.0)$ containing 1\% NP-40, $150 \mathrm{mM} \mathrm{NaCl}$, $100 \mu \mathrm{g} / \mathrm{ml}$ phenylmethylsulfonyl fluoride and $0.1 \%$ SDS. Lysis was performed on ice and lysates were subsequently denatured at $100^{\circ} \mathrm{C}$ for $10 \mathrm{~min}$. A Pierce bicinchoninic acid protein assay kit (Invitrogen; Thermo Fisher Scientific, Inc.) was used to measure the protein concentration and $30-\mu \mathrm{g}$ protein was loaded into each well. Proteins were separated by $10 \%$ SDS-PAGE and transferred to polyvinylidene fluoride membranes. The membranes were blocked in $3 \%(\mathrm{w} / \mathrm{v})$ bovine serum albumin for $1 \mathrm{~h}$ at room temperature. The primary antibodies used were as follows: Rabbit polyclonal ILF2 (cat. no. ab154791; 1:5,000), the rabbit polyclonal PTEN (cat. no. ab31392; $1: 1,000)$ and the mouse monoclonal GAPDH (cat. no. ab8245; 1:5,000; all from Abcam, Cambridge, UK), which were all dissolved in $5 \%$ bovine serum albumin $(\mathrm{w} / \mathrm{v})$. The primary antibodies were incubated with the membranes at $4^{\circ} \mathrm{C}$ overnight. The secondary antibodies used were the goat anti-rabbit immunoglobulin (Ig) G H\&L (cat. no. ab6721; 1:1,000) and the goat anti-mouse IgG H\&L (cat. no. ab6789; 1:1,000; all from Abcam), which were all dissolved in 3\% bovine serum albumin (w/v). The secondary antibodies were incubated with the blots at room temperature for $2 \mathrm{~h}$. Bands were visualized with using chemiluminescent horse radish peroxidase substrate (EMD Millipore, Billerica, MA, USA). X-ray films (Beijing Solarbio Science \& Technology Co., Ltd., Beijing, China) and a GE Amersham Imager 600 (GE Healthcare, Chicago, IL, USA) were used for signal detection.

Cloning and transfection. Human ILF2 and PTEN were amplified from H460 and HUVEC-C cDNA using Platinum ${ }^{\circledR}$ Taq DNA Polymerase (Invitrogen; Thermo Fisher Scientific, Inc.), respectively. The thermocycling conditions were as follows: Initial denaturation for $5 \mathrm{~min}$ at $95^{\circ} \mathrm{C}$; followed by 35 cycles of $30 \mathrm{sec}$ at $95^{\circ} \mathrm{C}, 30 \mathrm{sec}$ at $55^{\circ} \mathrm{C}$ and $2 \mathrm{~min}$ at $72^{\circ} \mathrm{C}$; and a final extension for $5 \mathrm{~min}$ at $72^{\circ} \mathrm{C}$. ILF2 and PTEN were ligated into the lentiviral shuttle pCCL.PPT.hPGK.IRES GFP/pre. The sequences of the primers used for amplification were as follows: ILF2-ORF, forward 5'-CGCGGATCCATG AGGGGTGACAGAGGCCG-3', reverse 5'-CGCGGATCC TCACTCCTGAGTTTCCATGC-3'; and PTEN-ORF, forward 5'-CGCGGATCCATGACAGCCATCATCAAAGA-3' and reverse 5'-CGCGGATCCTCAGACTTTTGTAATTTGTG-3'. Oligos encoding short hairpin (sh)RNA specific for ILF2 were ligated into pSUPER.retro.puro, and the fragment containing the $\mathrm{H} 1$ promoter and hairpin sequences was subcloned into the lentiviral shuttle pCCL.PPT.hPGK.GFP.Wpre. The shRNA sequences were as follows: shRNA-1 targeting ILF2, GGCCTT GCTGAAGAGGAATCA; shRNA-2 targeting ILF2, CTG TGATGAACAACCCCACCA; shRNA-1 targeting PTEN, GAAAGGGACGAACTGGTGTAA; and shRNA-2 targeting PTEN, GGCGTATACAGGAACAATATT. HEK293T was used for lentiviral packaging. A total of $15 \mathrm{ng}$ target plasmid was transfected into HEK293T with a confluence of $80 \%$ in $100 \mathrm{~mm}$ dishes. Polyethylenimine (Polysciences, Inc., Mount Arlington, NJ, USA) was used as the transfection reagent and a 1:3 transfection reagent: Plasmid ratio was used. Cells were transfected for $4 \mathrm{~h}$ in DMEM, after which the media was replaced. Cells were incubated at $37^{\circ} \mathrm{C}$ after transfection and the lentivirus was collected $24 \mathrm{~h}$ after transfection. Lentivirus was used to infect the corresponding target cells for $24 \mathrm{~h}$.
Chromatin immunoprecipitation (ChIP). ChIP was performed as described by Liu and Garrard (25). The primary antibody against ILF2 was used at a 1:50 dilution.

Luciferase reporter gene technology. DNA fragments of the PTEN upstream regulatory region were amplified from HUVEC-C DNA using Platinum ${ }^{\circledR}$ Taq DNA Polymerase (Invitrogen; Thermo Fisher Scientific, Inc.). Cycling conditions were as follows: Initial denaturation for $5 \mathrm{~min}$ at $95^{\circ} \mathrm{C}$, followed by 35 cycles of $30 \mathrm{sec}$ at $95^{\circ} \mathrm{C}, 30 \mathrm{sec}$ at $55^{\circ} \mathrm{C}$ and $2 \mathrm{~min}$ at $72^{\circ} \mathrm{C}$, with a final extension for $5 \mathrm{~min}$ at $72^{\circ} \mathrm{C}$. They were inserted into the XhoI and the HindIII sites of pGL3-basic with firefly luciferase. A Renilla reniformis luciferase plasmid (pRL-TK) was used for normalization. A549 and H460 cells $\left(1 \times 10^{5}\right)$ were plated in 24-well plates and were transfected after $\sim 24 \mathrm{~h}$, once they reached $\sim 80 \%$ confluence. Cells were co-transfected with $900 \mathrm{ng}$ target plasmid and $15 \mathrm{ng}$ pRL-TK using $1 \mu$ l Lipofectamine ${ }^{\circledR} 2000$ (Invitrogen; Thermo Fisher Scientific, Inc.) at $37^{\circ} \mathrm{C}$ in a cell culture incubator. After $24 \mathrm{~h}$, the Dual-Luciferase Reporter assay system (Promega Corporation, Madison, WI, USA) was used to lyse the cells and measure the luciferase activity with a Promega GloMax 20/20 Luminometer in Eppendorf Tubes according to the manufacturer's protocol.

Statistical analysis. SPSS v.19.0 software (IBM Corp., Armonk, NY, USA) was used to perform statistical analyses. Data are presented as the means \pm standard deviation. Comparison analysis was performed using the Student's t-test and one-way analysis of variance. Dunnett's test was used for pairwise comparisons of multiple treatment groups with a single control group. All experimental groups were compared to the control groups. $\mathrm{P}<0.05$ was considered to indicate a statistically significant difference. Kaplan-Meier survival analysis of ILF2 was performed with an online tool (http://kmplot.com/analysis/) and the log rank test was used to generate P-values.

\section{Results}

ILF2 is highly expressed in NSCLC cell lines and is associated with poor patient outcomes. ILF2 expression levels were detected in the human normal cell lines HUVEC-C, HBEC-5i and BEAS-2B, and in the NSCLC cell lines A549, H460, $\mathrm{H} 1155$ and H1299. High transcriptional and translational levels of ILF2 were detected in all NSCLC cell lines according to the results from RT-qPCR and western blotting experiments, respectively (Fig. 1A and $\mathrm{B}$ ).

In order to investigate the effect of ILF2 in lung cancer, Kaplan-Meier survival analysis was used to determine the association between ILF2 expression and the survival time of patients with lung cancer using an online tool (http://kmplot. com/analysis/) (26). The results demonstrated that increased ILF2 expression was significantly associated with a worse overall survival rate of patients with lung cancer $(n=2,437$; $\mathrm{P}=0.000088$; Fig. 1C), which suggested that ILF2 may serve a crucial role in lung cancer malignancy progression.

ILF2 reduces cell-matrix adhesion and promotes anchorage independence. To determine the role of ILF2 in the 
A
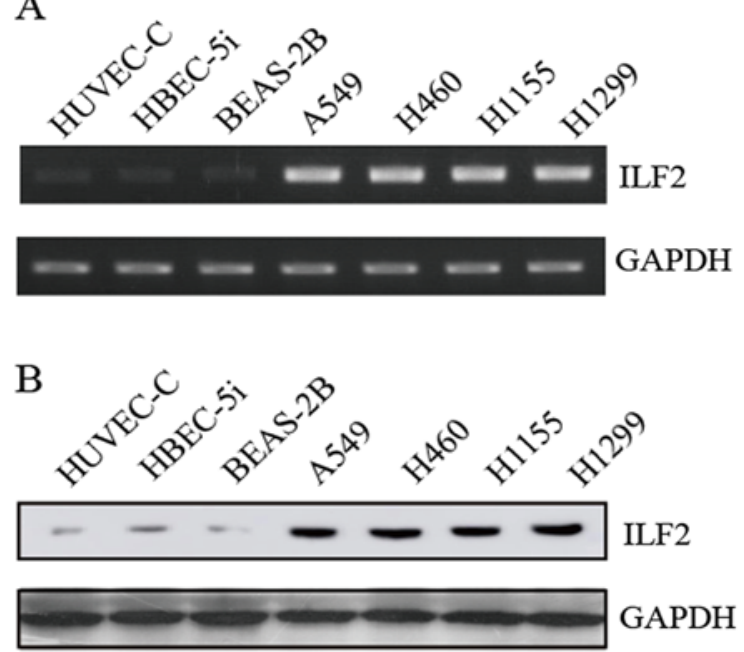

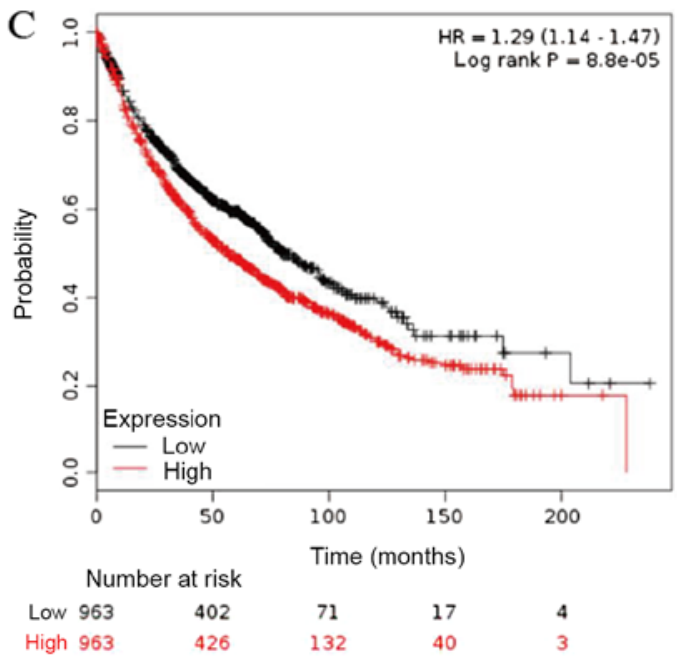

Figure 1. ILF2 is highly expressed in NSCLC cell lines and is associated with poor patient outcome. (A) Representative gel presenting mRNA expression of ILF2 in HUVEC-C, HBEC-5i, BEAS-2B, A549, H460, H1155 and H1299 cell lines. (B) Protein levels of ILF2 were measured by western blotting in HUVEC-C, HBEC-5i, BEAS-2B, A549, H460, H1155 and H1299 cell lines. (C) Kaplan-Meier survival analysis of the association between survival time and ILF2 signature in lung cancer using an online tool (http://kmplot.com/analysis/). ILF2, interleukin enhancer binding factor 2.

development of NSCLC, a series of cytology tests were conducted. Although it has been reported that ILF2 affects NSCLC cell proliferation (12), the results from the present study demonstrated a different effect. HUVEC-C and HBEC-5i were the normal cell lines used. A previous study demonstrated that, HUVEC-C and HBEC-5i are sensitive to anoikis (22), which may aid determining the function and underlying mechanism of ILF2. Western blotting demonstrated that ILF2 overexpression in HUVEC-C and HBEC-5i cells using the lentivirus system was successful (Fig. 2A). In addition, the adhesion assay reported that ILF2 significantly reduced cell adhesion (Fig. 2B). Furthermore, following $24 \mathrm{~h}$ of suspension culture, the survival rate of floating cells overexpressing ILF2 decreased compared with the control cells, as measured with the Cell Death Detection ELISA PLUS kit (Fig. 2C). The results obtained from HBEC-5i cell line were similar (data not shown). Furthermore, ILF2 knockdown in A549 and H460 cells confirmed these phenomena (Fig. 2D-F). Western blotting confirmed ILF2 knockdown in A549 and H460 cell lines (Fig. 2D). In addition, ILF2 knockdown significantly increased cell adhesion and reduced cell survival after suspension culture (Fig. 2E and F, respectively). The results obtained from the $\mathrm{H} 460$ cell line were similar (data not shown). Taken together, these results suggested that ILF2 may reduce cell-cell and cell-matrix adhesions and promote anchorage independence.

ILF2 promotes anchorage independence by inhibiting PTEN expression. The results demonstrated that ILF2 overexpression in HUVEC-C and HBEC-5i cell lines decreased the PTEN protein level (Fig. 3A). It has been reported that PTEN affects many aspects of tumor progression, including apoptosis promotion (27). Following PTEN knockdown by shRNA in HUVEC-C, the cell phenotype was similar (Fig. 3B and C) to the one observed following ILF2 overexpression. The results obtained from HBEC-5i cell line were similar (data not shown). These results suggested that ILF2 may reduce cell adhesion and promote anchorage independence by inhibiting PTEN expression. To test this hypothesis, the PTEN expression decrease caused by ILF2 overexpression was recovered by overexpressing PTEN. Cell adhesion and apoptosis after suspension culture recovered to some degree (Fig. 3B and C).

ILF2 knockdown in A549 and H460 cell lines led to PTEN upregulation (Fig. 3D). PTEN recovery reduced cell-matrix adhesion and stimulated cell survival following $24 \mathrm{~h}$ of suspension culture (Fig. 3E and F). The results obtained from the H460 cell line were similar (data not shown). These data indicated that ILF2 reduced cell adhesion and promoted anchorage independence by regulating PTEN expression.

ILF2 can directly bind to PTEN gene to regulate its transcription. The specific mechanism of ILF2 on PTEN regulation was further explored. Since ILF2 is a transcription factor, it was hypothesized that it could bind to the PTEN gene upstream to regulate its transcription. It has been reported that ILF2 interacts with the TGACAA motif of IL-2 proximal promoter (28). According to DNase I hypersensitive sites analyzed by the Encyclopedia of DNA Elements at the UCSC database (http://genome.ucsc.edu/ENCODE/), a series of primers for ChIP assays in the range of $10 \mathrm{~kb}$ upstream and downstream of the PTEN transcription start site were designed (Fig. 4A). In HUVEC-C and HBEC-5i cells overexpressing ILF2, the results from the ChIP assay demonstrated that ILF2 could bind to the R3 region of PTEN (Fig. 4B and C). A series of luciferase reporter vectors containing fragments of different lengths upstream of PTEN were then constructed. A549 and H460 cells highly expressing ILF2 were used to conduct the luciferase reporter gene assays. The results demonstrated that the activity of the luciferase reporter containing the $-2,956$ to $-2,642$ bp fragment was very high (Fig. 4D). Furthermore, the position of the $-2,956$ to $-2,642$ bp fragment overlaps with the R3 position. These results indicated that the transcription factor ILF2 bound directly to the upstream region of the PTEN gene to affect its expression. 
A

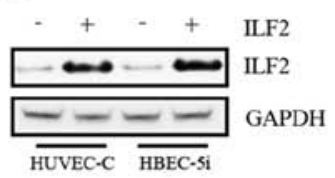

B

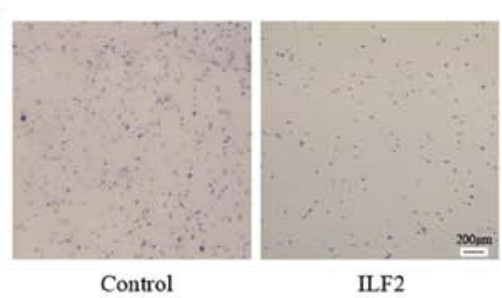

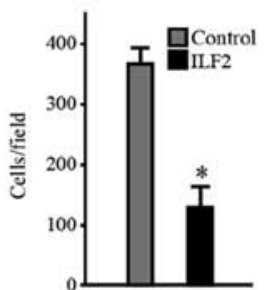

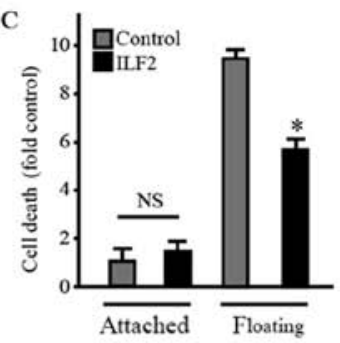

E

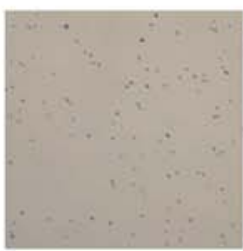

con shRNA

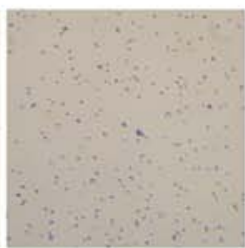

shILF2-1

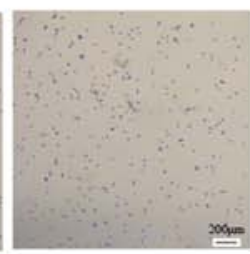

shILF2-2
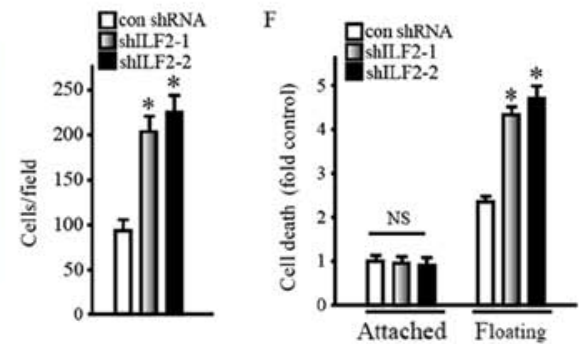

Figure 2. ILF2 reduces cell-matrix adhesion and promotes anchorage independence. (A) Western blotting confirmed that ILF2 was successfully overexpressed in HUVEC-C and HBEC-5i cell lines. (B) Overexpression of ILF2 reduced the adhesion ability of HUVEC-C cells. Scale bars, $200 \mu \mathrm{m}$. (C) Resistance to anoikis was increased in suspended HUVEC-C cells following ILF2 overexpression. Results from same assay in HBEC-5i were similar (data not shown). ${ }^{*} \mathrm{P}<0.05$ vs. control. (D) Western blotting confirmed successful knockdown of ILF2 in A549 and H460 cell lines. (E) ILF2 knockdown increased adhesion ability of A549 cells. Scale bars, $200 \mu \mathrm{m}$. (F) Ratio of suspended A549 cells undergoing anoikis was increased following ILF2 knockdown. Results from same assays in $\mathrm{H} 460$ were similar (data not shown). ${ }^{*} \mathrm{P}<0.05$ vs. con shRNA. Attached, cells attached to the extracellular matrix; floating, cells suspended without the extracellular matrix; con, control; ILF2, interleukin enhancer binding factor 2; NS, not significant; sh, short hairpin.
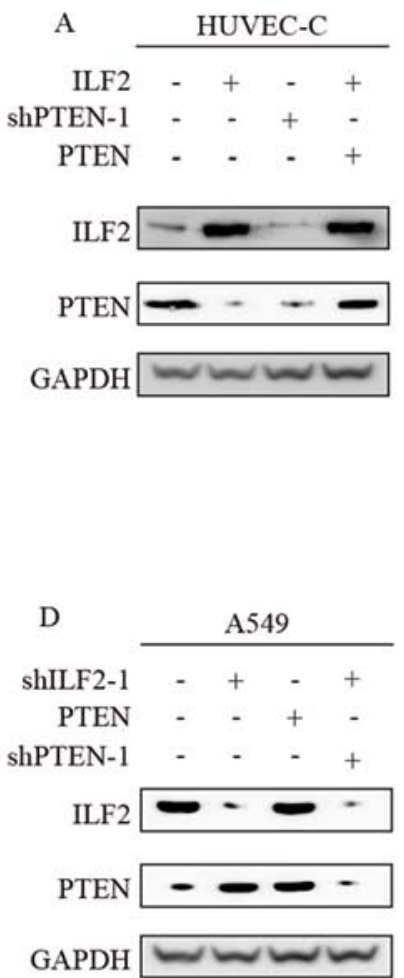

B

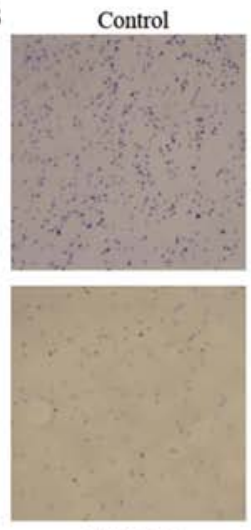

ShPTEN-1

E

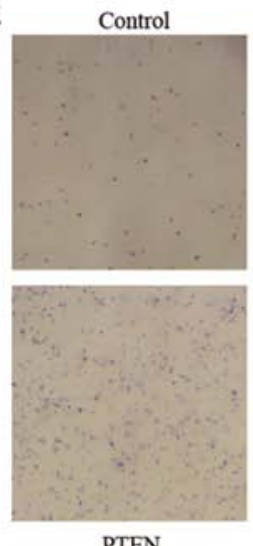

ILF2

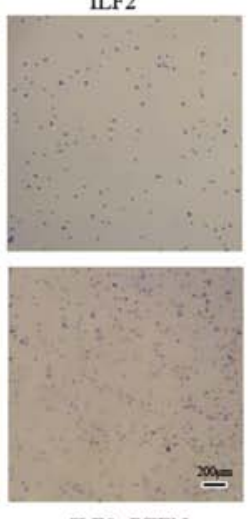

ILF2+PTEN
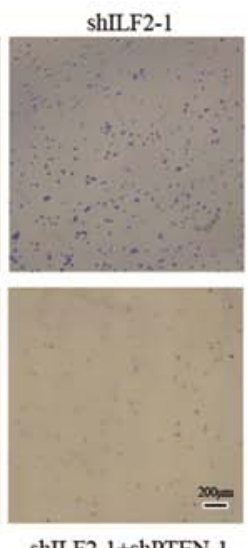

ShILF2-1+shPTEN-1

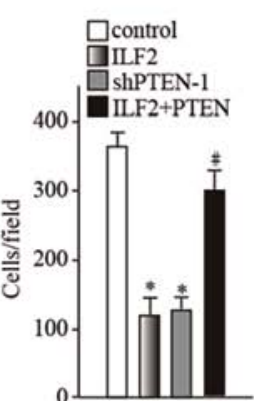

$\mathrm{C}$
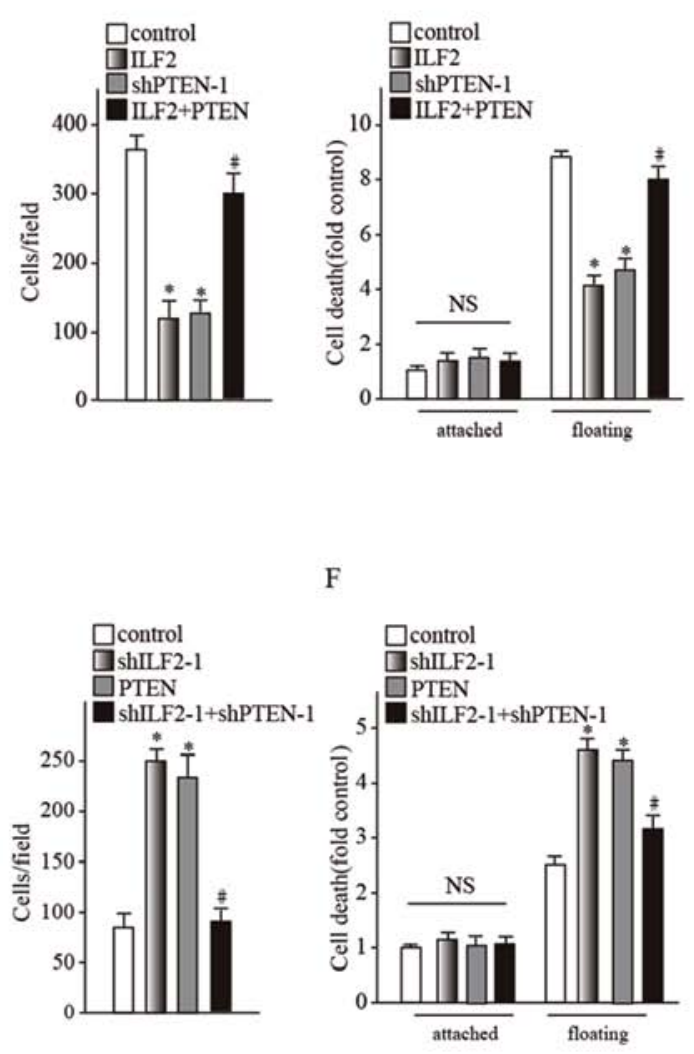

Figure 3. ILF2 promotes anchorage independence by inhibiting PTEN expression. (A) Western blotting was performed on HUVEC-C cells to determine the expression of ILF2 and PTEN protein. (B) Adhesion ability and (C) anoikis were measured in HUVEC-C cells following infection with lentivirus. Results from same assays in HBEC-5i cells were similar (data not shown). (D) Western blotting was performed on A549 cells to determine the expression of ILF2 and PTEN protein. (E) Adhesion ability and (F) anoikis were measured in A549 cells following transfection. For anoikis, the rate of cell death was assessed following $24 \mathrm{~h}$ of suspension in culture. Results from same assays in $\mathrm{H} 460$ cells were similar (data not shown). ${ }^{*} \mathrm{P}<0.05$ vs. control; ${ }^{*} \mathrm{P}<0.05 \mathrm{vs}$. ILF2 or shILF2-1 group. Attached, cells attached to the extracellular matrix; floating, cells suspended without the extracellular matrix; ILF2, interleukin enhancer binding factor 2; NS, not significant; PTEN, phosphatase and tensin homolog deleted on chromosome ten; sh, short hairpin. 
A

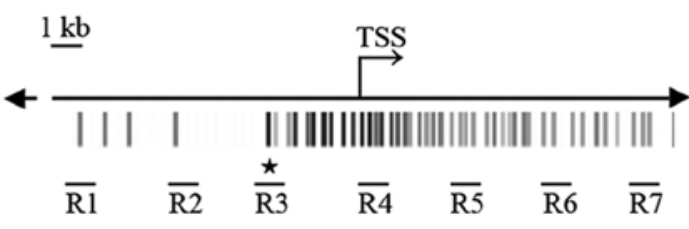

C

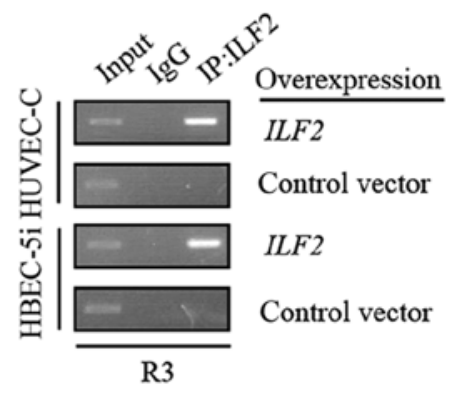

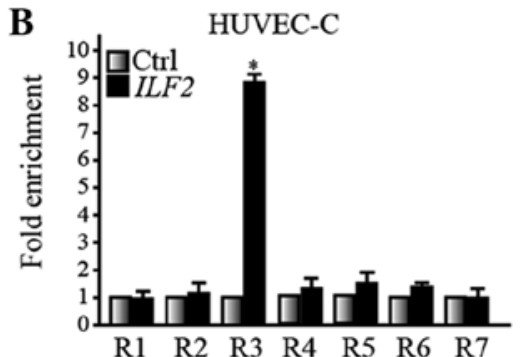

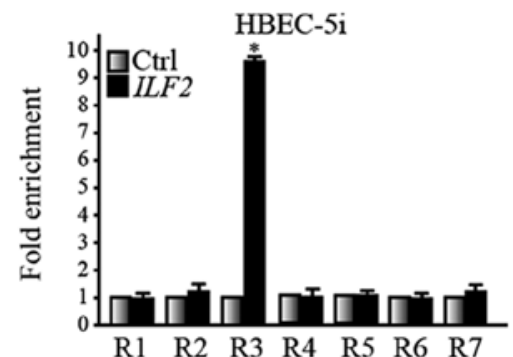

D
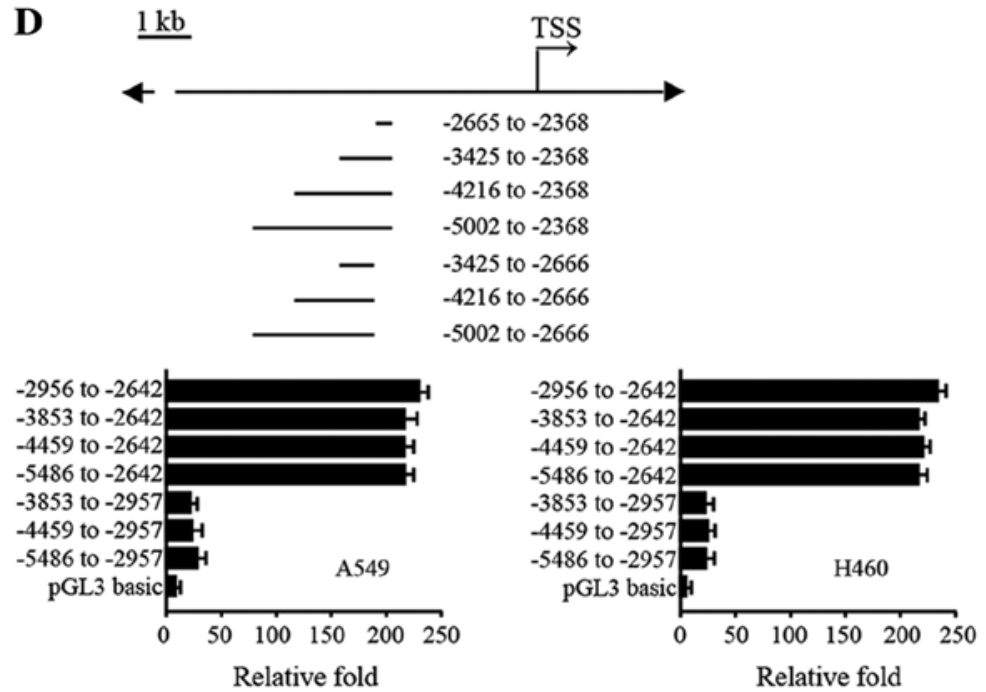

Figure 4. ILF2 can directly bind to the PTEN gene to regulate its transcription. (A) The seven regions designed for ChIP are highlighted. (B) ChIP analysis demonstrated that ILF2 antibody was enriched in the region R3 of PTEN in HUVEC-C and HBEC-5i cell lines following ILF2 overexpression, according to RT-qPCR results. (C) Representative gel for R3 of PTEN following ChIP analysis of HUVEC-C and HBEC-5i cell lines that overexpressed ILF2, according to RT-qPCR results. (D) Luciferase reporter studies indicated that the region of PTEN regulated by ILF2 may be located within the -2956 to -2642 bp fragment. Asterisks indicate site with ILF2 consensus sequences. ChIP, chromatin immunoprecipitation; Ctrl, control; IgG, immunoglobulin G; ILF2, interleukin enhancer binding factor 2; PTEN, phosphatase and tensin homolog deleted on chromosome ten; R3, region 3; TSS, transcriptional start site; Ctrl, control.

\section{Discussion}

Lung cancer is one of the most common malignancies worldwide. NSCLC includes squamous cell carcinoma, adenocarcinoma and large cell carcinoma. In comparison with small cell carcinoma, NSCLC cells have slower growth and division rates, and diffusion and metastasis occur relatively late. NSCLC accounts for $\sim 80 \%$ of all lung cancers. At the time of diagnosis, $75 \%$ of patients with NSCLC are in advanced stages and have a poor 5-year survival rate of $\sim 16 \%$. The majority of patients with NSCLC are elderly, and $~ 50 \%$ of patients with lung cancer are $>65$ years old (29). Early diagnosis of NSCLC is essentially based on sputum cytology examination, chest X-ray and other related examinations (30). Patients are conventionally treated by chemotherapy combined with surgery; however, the overall efficiency remains poor (31). With the major breakthrough and rapid development of the Human Genome Project, the diagnosis and treatment of lung tumors has reached the molecular level. Due to genetic engineering, novel discoveries have been made at the gene level, which has attracted the attention of the medical community (31).

ILF2 is a transcription factor that contains an internal ribosome entry site. ILF2 interacts with ILF3 to form a complex that affects the nuclear redistribution of mRNA, repairs non-homologous end-linked DNA damage, negatively regulates the processing of microRNA and affects the expression of downstream genes (32-34). The main biological function of ILF2 is the control of cell cycle and apoptosis. However, these biological roles are cell type-specific. For example, ILF2 is lowly expressed in the liver, heart, lung, skeletal muscle and spleen, whereas it is highly expressed in kidney, testis, thymus and brain (35). The results from the present study demonstrated that ILF2 high expression was associated with NSCLC cell detachment and survival.

Previous studies reported abnormal ILF2 expression in cervical and colorectal cancers $(36,37)$. By analyzing Kaplan-Meier prognosis data of NSCLC, it was demonstrated that high ILF2 expression was associated with poor prognosis in the present study. A series of experiments were conducted to examine the specific functions of ILF2 in NSCLC cell lines here. The results demonstrated that ILF2 was highly expressed in NSCLC cells and reduced adhesion in cells, and promoted cell survival independently of anchorage. In addition, ILF2 achieved these functions by binding to the upstream regulatory region of the PTEN gene to inhibit its expression.

Although the present study was not the first to explore the function of ILF2 in NSCLC cells, novel features have been demonstrated. To the best of our knowledge, this study was the first to explore the association between the transcription factor ILF2 and the tumor suppressor gene PTEN in NSCLC cell lines. These results may aid scientists and clinicians to better 
understand NSCLC in order to provide novel molecular targets for diagnosis and treatment.

The present study demonstrated that high expression of ILF2 could cause weak cell adhesion to the extracellular matrix and anoikis resistance. These two phenomenons may be influenced by the ILF2/PTEN pathway. A previous study revealed that cells reduced adhesion and bypassed anoikis by down-regulating the integrin-signaling pathway (38). ILF2/PTEN pathway may also achieve these functions by affecting the integrin signaling pathway, which requires further investigation. Integrin expression and related signaling pathways will be examined in a future study.

\section{Acknowledgements}

Not applicable.

\section{Funding}

No funding was received.

\section{Availability of data and materials}

The datasets used or analyzed during the present study are available from the corresponding author on reasonable request.

\section{Authors' contributions}

TL designed the present study, and prepared, edited and reviewed the manuscript. NL, HL and LFZ performed the experiments. NL, LPC and MYG acquired the data. NL, WKH and QZQ analyzed the data. QGM, JHZ and JZ performed the statistical analysis.

\section{Ethics approval and consent to participate}

Not applicable.

\section{Patients consent for publication}

Not applicable.

\section{Competing interests}

The authors declare that they have no competing interests.

\section{References}

1. Fernandez LE, Gabri MR, Guthmann MD, Gomez RE, Gold S, Fainboim L, Gomez DE and Alonso DF: NGcGM3 ganglioside: A privileged target for cancer vaccines. Clin Dev Immunol 2010: 814397, 2010.

2. Ladanyi $\mathrm{M}$ and Pao W: Lung adenocarcinoma: Guiding EGFR-targeted therapy and beyond. Mod Pathol 21 (Suppl 2): S16-S22, 2008

3. Zhan P, Wang J, Lv XJ, Wang Q, Qiu LX, Lin XQ, Yu LK and Song Y: Prognostic value of vascular endothelial growth factor expression in patients with lung cancer: A systematic review with meta-analysis. J Thorac Oncol 4: 1094-1103, 2009.

4. Siegel RL, Miller KD and Jemal A: Cancer statistics, 2015. CA Cancer J Clin 65: 5-29, 2015.

5. Wyllie AH: 'Where, $\mathrm{O}$ death, is thy sting?' A brief review of apoptosis biology. Mol Neurobiol 42: 4-9, 2010.
6. Ruoslahti E and Reed JC: Anchorage dependence, integrins, and apoptosis. Cell 77: 477-478, 1994.

7. Cheng TL, Symons M and Jou TS: Regulation of anoikis by Cdc42 and Rac1. Exp Cell Res 295: 497-511, 2004.

8. Frankel A, Rosen K, Filmus J and Kerbel RS: Induction of anoikis and suppression of human ovarian tumor growth in vivo by down-regulation of Bcl-X(L). Cancer Res 61: 4837-4841, 2001.

9. Yamada KM and Araki M: Tumor suppressor PTEN: Modulator of cell signaling, growth, migration and apoptosis. J Cell Sci 114: 2375-2382, 2001.

10. Zhan M, Zhao H and Han ZC: Signalling mechanisms of anoikis. Histol Histopathol 19: 973-983, 2004.

11. Huang Q, He X, Qiu X, Liu X, Sun G, Guo J, Ding Z, Yang L, Ban N, Tao T and Wang D: Expression of NF45 correlates with malignant grade in gliomas and plays a pivotal role in tumor growth. Tumour Biol 35: 10149-10157, 2014.

12. Ni T, Mao G, Xue Q, Liu Y, Chen B, Cui X, Lv L, Jia L, Wang Y and Ji L: Upregulated expression of ILF2 in non-small cell lung cancer is associated with tumor cell proliferation and poor prognosis. J Mol Histol 46: 325-335, 2015.

13. Ni S, Zhu J, Zhang J, Zhang S, Li M, Ni R, Liu J, Qiu H, Chen W, Wang $\mathrm{H}$ and Guo W: Expression and clinical role of NF45 as a novel cell cycle protein in esophageal squamous cell carcinoma (ESCC). Tumour Biole 36: 747-756, 2015.

14. Haselmann V, Kurz A, Bertsch U, Hübner S, Olempska-Müller M, Fritsch J, Häsler R, Pickl A, Fritsche H, Annewanter F, et al: Nuclear death receptor TRAIL-R2 inhibits maturation of let-7 and promotes proliferation of pancreatic and other tumor cells. Gastroenterology 146: 278-290, 2014.

15. Wan C, Gong C, Ji L, Liu X, Wang Y, Wang L, Shao M, Yang L, Fan S, Xiao Y, et al: NF45 overexpression is associated with poor prognosis and enhanced cell proliferation of pancreatic ductal adenocarcinoma. Mol Cell Biochem 410: 25-35, 2015.

16. Lee YY, McKinney KQ, Ghosh S, Iannitti DA, Martinie JB, Caballes FR, Russo MW, Ahrens WA, Lundgren DH, Han DK, et al: Subcellular tissue proteomics of hepatocellular carcinoma for molecular signature discovery. J Proteome Res 10: 5070-5083, 2011.

17. Li J, Yen C, Liaw D, Podsypanina K, Bose S, Wang SI, Puc J, Miliaresis C, Rodgers L, McCombie R, et al: PTEN, a putative protein tyrosine phosphatase gene mutated in human brain, breast, and prostate cancer. Science 275: 1943-1947, 1997.

18. Datta SR, Brunet A and Greenberg ME: Cellular survival: A play in three Akts. Genes Dev 13: 2905-2927, 1999.

19. Sulis ML and Parsons R: PTEN: From pathology to biology. Trends Cell Biol 13: 478-483, 2003.

20. Tamura M,Gu J, Matsumoto K, Aota S, Parsons R and Yamada KM: Inhibition of cell migration, spreading, and focal adhesions by tumor suppressor PTEN. Science 280: 1614-1617, 1998.

21. Zhong H, Chiles K, Feldser D, Laughner E, Hanrahan C, Georgescu MM, Simons JW and Semenza GL: Modulation of hypoxia-inducible factor 1alpha expression by the epidermal growth factor/phosphatidylinositol 3-kinase/PTEN/AKT/FRAP pathway in human prostate cancer cells: Implications for tumor angiogenesis and therapeutics. Cancer Res 60: 1541-1545, 2000.

22. Li X, Xu Z, Du W, Zhang Z, Wei Y, Wang H, Zhu Z, Qin L, Wang L, Niu Q, et al: Aiolos promotes anchorage independence by silencing p66Shc transcription in cancer cells. Cancer Cell 25: 575-589, 2014.

23. Liu CY, Takemasa A, Liles WC, Goodman RB, Jonas M, Rosen H, Chi E, Winn RK, Harlan JM and Chuang PI: Broad-spectrum caspase inhibition paradoxically augments cell death in TNF-alpha-stimulated neutrophils. Blood 101: 295-304, 2003.

24. Livak KJ and Schmittgen TD: Analysis of relative gene expression data using real-time quantitative PCR and the 2(-Delta Delta C(T)) method. Methods 25: 402-408, 2001.

25. Liu Z and Garrard WT: Long-range interactions between three transcriptional enhancers, active Vkappa gene promoters, and a 3 ' boundary sequence spanning 46 kilobases. Mol Cell Biol 25: 3220-3231, 2005.

26. Gyôrffy B, Surowiak P, Budczies J and Lánczky A: Online survival analysis software to assess the prognostic value of biomarkers using transcriptomic data in non-small-cell lung cancer. PLoS One 8: e82241, 2013.

27. Di Cristofano A and Pandolfi PP: The multiple roles of PTEN in tumor suppression. Cell 100: 387-390, 2000.

28. Shi L, Qiu D, Zhao G, Corthesy B, Lees-Miller S, Reeves WH and Kao PN: Dynamic binding of Ku80, Ku70 and NF90 to the IL-2 promoter in vivo in activated T-cells. Nucleic Acids Res 35: 2302-2310, 2007. 
29. Reck M,Heigener DF, Mok T, Soria JC and Rabe KF: Management of non-small-cell lung cancer: Recent developments. Lancet 382: 709-719, 2013

30. Goldstraw P, Ball D, Jett JR, Le Chevalier T, Lim E, Nicholson AG and Shepherd FA: Non-small-cell lung cancer. Lancet 378 : 1727-1740, 2011

31. Tan WL, Jain A, Takano A, Newell EW, Iyer NG, Lim WT Tan EH, Zhai W, Hillmer AM, Tam WL and Tan DSW: Novel therapeutic targets on the horizon for lung cancer. Lancet Oncol 17: e347-e362, 2016.

32. Karmakar S, Mahajan MC,Schulz V, Boyapaty G and Weissman SM: A multiprotein complex necessary for both transcription and DNA replication at the $\beta$-globin locus. EMBO J 29: 3260-3271, 2010.

33. Shamanna RA, Hoque M, Lewis-Antes A, Azzam EI, Lagunoff D, Pe'ery T and Mathews MB: The NF90/NF45 complex participates in DNA break repair via nonhomologous end joining. Mol Cell Biol 31: 4832-4843, 2011.

34. Volk N and Shomron N: Versatility of MicroRNA biogenesis. PLoS One 6: e19391, 2011.
35. Zhao G, Shi L, Qiu D, Hu H and Kao PN: NF45/ILF2 tissue expression, promoter analysis, and interleukin-2 transactivating function. Exp Cell Res 305: 312-323, 2005.

36. Shim C, Zhang W, Rhee $\mathrm{CH}$ and Lee JH: Profiling of differentially expressed genes in human primary cervical cancer by complementary DNA expression array. Clin Cancer Res 4: 3045-3050, 1998

37. Chung FH, Lee HH and Lee HC: ToP: A trend-of-diseaseprogression procedure works well for identifying cancer genes from multi-state cohort gene expression data for human colorectal cancer. PLoS One 8: e65683, 2013.

38. Overholtzer M, Mailleux AA, Mouneimne G, Normand G, Schnitt SJ, King RW, Cibas ES and Brugge JS: A nonapoptotic cell death process, entosis, that occurs by cell-in-cell invasion. Cell 131: 966-979, 2007.

(i) (9) This work is licensed under a Creative Commons Attribution-NonCommercial-NoDerivatives 4.0 International (CC BY-NC-ND 4.0) License. 